\title{
Surface Functionalized Halloysite with N-[3- (Trimethoxysilyl)Propyl] Ethylenediamine for Chromium and Nickel Adsorption from Aqueous Solution
}

\author{
Sulyani Fitri ${ }^{1(\mathbb{C})}$, Amri Yahya ${ }^{1(\mathbb{D})}$, Sheikh Ahmad Izaddin Sheikh Mohd Ghazali ${ }^{2}{ }^{\mathbb{D}}$, Is Fatimah ${ }^{1(\mathbb{C})}$ \\ 1 Department of Chemistry, Faculty of Mathematics and Natural Sciences, Universitas Islam Indonesia, Kampus Terpadu \\ UII, Jl. Kaliurang Km 14, Sleman, Yogyakarta, Indonesia; isfatimah@uii.ac.id (I.F.); \\ 2 Faculty of Applied Sciences, Universiti Teknologi MARA Cawangan Negeri Sembilan, Kampus Kuala Pilah, Kuala Pilah \\ 72000, Negeri Sembilan, Malaysia; \\ * Correspondence: isfatimah@uii.ac.id (I.F.);
}

Received: 10.09.2021; Revised: 25.10.2021; Accepted: 29.10.2021; Published: 24.11.2021

\begin{abstract}
In this study, -[3-(trimethoxysilyl)propyl] ethylenediamine - modified Indonesian natural halloysite was applied for $\mathrm{Cr}$ (III) and $\mathrm{Ni}$ (II) adsorption from aqueous solution. The studies include the physicochemical characterization of the synthesized material by using XRD, SEM, gas sorption analyzer, and FTIR analyses. Furthermore, the adsorption experiments were performed at a batch system for investigating the adsorption kinetics and thermodynamic. The results showed no significant changes in either the material crystallinity or specific surface area, but the changes of surface functional groups identified the anchored ammine modifier. Kinetic modeling showed pseudo-second-order model best fitted the experimental data for both adsorbents. Moreover, the thermodynamic studies represented the chemisorption interaction of modified halloysite with the adsorbate since the average adsorption enthalpy values are at $44.3 \mathrm{~kJ} / \mathrm{mol}$ and $41.70 \mathrm{~kJ} / \mathrm{mol}$ for $\mathrm{Cr}(\mathrm{III})$ and $\mathrm{Ni}(\mathrm{II})$, respectively.
\end{abstract}

Keywords: adsorption; kaolinite; chromium; nickel.

(C) 2021 by the authors. This article is an open-access article distributed under the terms and conditions of the Creative Commons Attribution (CC BY) license (https://creativecommons.org/licenses/by/4.0/).

\section{Introduction}

Considerable amounts of metals are used in many process industries, such as paint, ink, battery, and textile industries. The toxicity and fate of such metals, especially heavy metals, are the most concerned in industrial wastewater monitoring. Without proper treatment, the rest of the metal ions in aquatic and soil environments threats human health as they can easily be magnified and pre-concentrated by the food chain [1,2]. Due to these strong and serious reasons, the treatment of metal ions-containing wastewater needs to be optimized. Adsorption is the most popular method for uptake metal ions from the aquatic system due to its simplicity and ease in the operational scale. The development of high capacity and specificity of adsorbent is the most to get interested and attempted. Especially for heavy metals, including nickel and chromium, the searches of selective adsorbents with high capacity were recorded. In particular, to enhance the economic value of the adsorption process for many applications, the exploration of a low-cost adsorbent gets the most interest $[3,4]$.

Previous research reported the special feature of functional natural minerals-based materials for some heavy metals. The applicability of the silica-alumina surface to be modified 
with a specific functional group having affinity to trap with metal ion is the main characteristic for adsorption capacity enhancement. Naturally occurring clay minerals offer

great potential because of their characteristic structure as the layered and threedimensional formation $[5,6]$. The adjustable structure is the base for various technological applications based on the adsorptive and ionic. The use of natural minerals such as clay materials is valued to give economic value refer to the abundance source [3,7,8]. Within this topic, a previous paper has reported the functionalization of kaolinite with $\mathrm{N}$-[3(trimethoxysilyl)propyl] ethylenediamine, called APTES/Kaolinite for Pb(II) removal [9]. The anchored ammine functional group was significantly improving the adsorption capacity and reusability of $\mathrm{Pb}$ (II). However, there is no study on the removal of $\mathrm{Cr}$ (II) and $\mathrm{Ni}$ (II) by the material $[10,11]$.

By a similar clay class such as kaolinite, halloysite is one of the typical minerals that have gotten more interest recently $[12,13]$. The feature of halloysite, such as its easy to be converted into many forms by surface functionalization, make it attractive for selective adsorption [12]. Refer to the big potency of halloysite mineral in Indonesia and as an exploration to contribute the data for heavy metal adsorption, this paper reports the modification of Indonesian halloysite with $\mathrm{N}$-[3-(trimethoxysilyl)propyl] ethylenediamine [furthermore called as APTES/HAL] and the study for its capability in $\mathrm{Cr}$ (III) and $\mathrm{Ni}$ (II) adsorption from aqueous solution.

\section{Materials and Methods}

\subsection{Materials.}

Chemicals consisting of nickel chloride, chromium (III) nitrate, and N-[3(trimethoxysilyl)propyl] ethylenediamine were purchased from Merck (Germany). Halloysite sample was obtained from the mining area of East Java, Indonesia, were washed with tap water to remove impurities, dried in an oven, ground, and sieved to a particle size range of 100 mesh.

\subsection{Methods preparation of APTES/HAL.}

The preparation of APTES/HAL from halloysite powder was conducted to refer to previous work. An APTES solution was slowly added to a halloysite suspension of $10 \mathrm{~g}$ of kaolinite in $100 \mathrm{~mL}$ of distilled water. Into the mixture, $0.2 \mathrm{M} \mathrm{HCl}$ was added and stirred for $4 \mathrm{~h}$ followed by refluxing for $6 \mathrm{~h}$. The APTES content in the composite was set at $10 \mathrm{mmol} / \mathrm{g}$. The solid from the reflux was obtained by drying suspension in an oven, and the result was encoded as APTES/HAL.

\subsection{Characterization.}

The character of APTES/HAL and HAL samples was analyzed using x-ray diffraction, gas sorption analyzer, Fourier Transform Infrared (FTIR) spectrometer, and SEM analysis. A Shimadzu X6000 XRD instrument was employed for the analysis, and a gas sorption analyzer, SEM-EDX of Phenom X, was employed at $0.2 \mu \mathrm{m}$ resolution and a magnification of 10000x. Brunauer-Emmett-Teller (BET) measurements were performed on a NOVA 1200 quantachrom. The nitrogen adsorption isotherm values were determined at $77 \mathrm{~K}$.

The adsorption experiments were conducted in a batch system using a horizontal shaker. For each adsorption experiment, $0.2 \mathrm{~g}$ of the adsorbent was added into a $250 \mathrm{~mL}$ 
solution. The amount of rest metal ions was determined using atomic absorption spectrophotometer (AAS). A Perkin-Elmer instrument was utilized.

\subsection{Adsorption experiments.}

The adsorption experiments were conducted in a batch system. For the study, varied contact time, adsorbents, and temperatures were applied. The adsorbed metal ion was calculated based on the metal ion concentration in the filtrate, which was measured by atomic absorption spectrophotometry. A Perkin-Elmer instrument was employed for the analysis.

\section{Results and Discussion}

\subsection{Physicochemical character of the adsorbents.}

Fig.1 shows the diffractograms of HAL and APTES/HAL. The presence of HAL is identified by the sharp reflection at $2 \theta$ of $20.1^{\circ}$ which is the characteristic $\left(\begin{array}{lll}1 & 1 & 0\end{array}\right)$ halloysite together with the peaks at about $27.1^{\circ}$ and $43.8^{\circ}$ corresponding to $\left(\begin{array}{lll}0 & 0\end{array}\right)$ and $\left(\begin{array}{lll}1 & 2 & 3\end{array}\right)$ reflections, respectively [14]. Other peaks beside the halloysite representative are observed at around $30 \mathrm{o}$, referred to as alunite, and at about $37^{\circ}$ associated with the presence of kaolinite [15-17]. Both identified phases are usually found as the halloysite used here is the natural mineral. The APTES modification does not change the peaks presented, indicating that there was no chemical change during the process nor the physical influence.

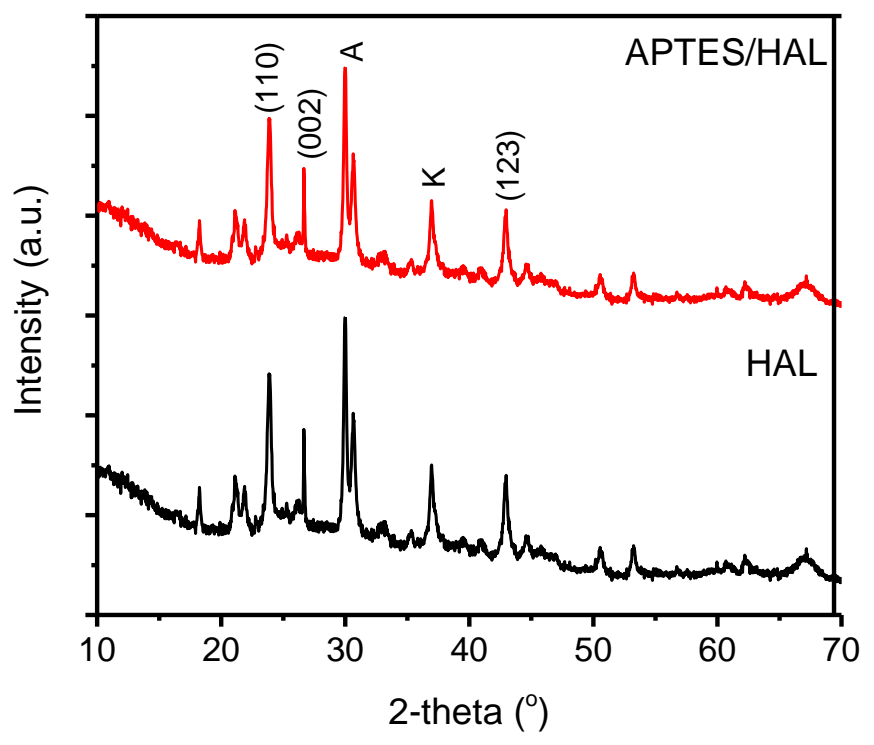

Figure 1. XRD pattern of HAL and APTES/HAL.

The FTIR spectra of HAL and APTES/HAL are presented in Fig.2.

Both solids show sharp and wide bands at the range of $3400-3690 \mathrm{~cm}^{-1}$, corresponding to the indication of $\mathrm{O}-\mathrm{H}$ coming from water and hydroxyl-associated with $\mathrm{Si}-\mathrm{O}$ and $\mathrm{Al}-\mathrm{O}$ from halloysite structure. These bands are also associated with the absorption at around 1637-1641 $\mathrm{cm}^{-1}$, indicating the presence of a $\mathrm{Si}-\mathrm{OH}$ group. The $\mathrm{Si}-\mathrm{O}$ is also identified by the emergence of strong bands in the $462 \mathrm{~cm}^{-1}$ together with the presence of Si-O-Si with the absorption at $1044 \mathrm{~cm}^{-1}$ and $800 \mathrm{~cm}^{-1}$. The attachment of APTES in APTES/HAL is identified with the vibration spectrum at $1384.12 \mathrm{~cm}^{-1}$ which indicates the vibration of primary $\mathrm{N}-\mathrm{H}$, and the vibration associated with $\mathrm{C}-\mathrm{H}$ at around $2885.51 \mathrm{~cm}-1$ coming from the propyl chain of 
APTMS structure. Similar characteristics bands were also identified by such amine-modified silica surface and ammine-modified clay $[9,18,19]$.

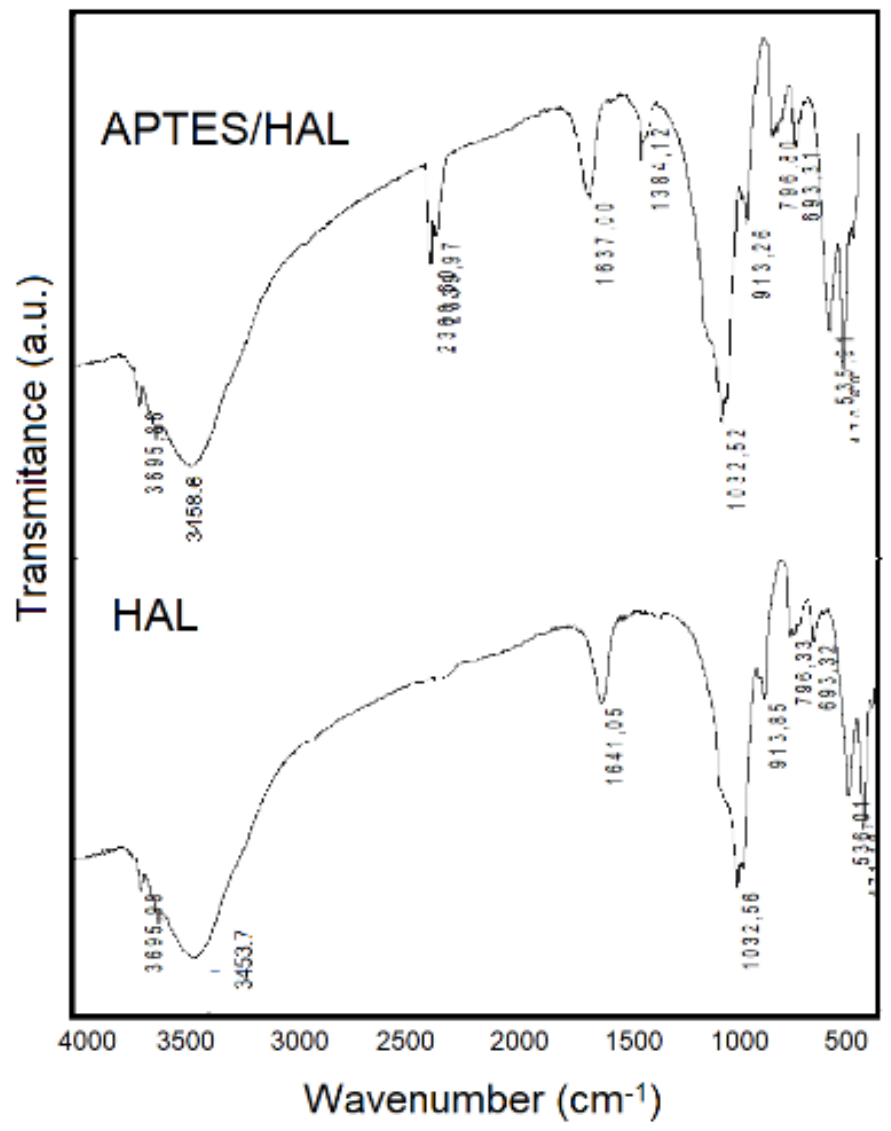

Figure 2. FTIR spectra of HAL and APTES/HAL.

The surface modification reflects the change of surface morphology as presented by SEM image in Fig.3. A relatively smoother surface is found in APTES/HAL; meanwhile, HAL represents the predefined characteristics morphology. From the EDX spectra, Si and Al are the main components of the materials with no significant change in amount. It was calculated that the $\mathrm{Si} / \mathrm{Al}$ molar ratio of about 1.02 is found, which represents the halloysite and silica component in the natural mineral [20]. However, as the surface evolution was identified, the specific surface area of APTES/HAL is about $37.4 \mathrm{~m}^{2} / \mathrm{g}$ which is not significantly different from HAL, which exhibits a specific surface area of about $39.7 \mathrm{~m}^{2} / \mathrm{g}$. A similar phenomenon was also reported in the APTES modification to kaolinite in that less surface area was found, but there is no such significant reduction [21].

The adsorption capability of the adsorbents was evaluated by measuring the adsorption capacity as a function of adsorption time, and the plot is presented in Fig.4.

From the plots, it can be seen that APTES/HAL gives a higher adsorption capacity compared to HAL at the time range of 30-120 min. The kinetics of the adsorption was evaluated refer to the pseudo-first-order, pseudo-second-order, and intra-particle diffusion kinetics by following equations (1-3):

$$
\begin{gathered}
\ln \left(q_{e}-q_{t}\right)=\ln q_{e}-k t \\
\frac{t}{q_{t}}=\frac{1}{k_{2} q_{e}^{2}}+\frac{t}{q_{e}} \\
q_{t}=k_{i} t^{0.5}+C
\end{gathered}
$$


where $q_{t}(\mathrm{mg} / \mathrm{g})$ is the amount of adsorbed metal ions at the time of $t, q_{e}(\mathrm{mg} / \mathrm{g})$ is adsorption capacity, $k\left(\mathrm{~min}^{-1}\right)$ is the first-order rate constant, $k_{2}(\mathrm{~g} / \mathrm{mg} \mathrm{min})$ is the second-order rate constant of adsorption $\left(\mathrm{min}^{-1}\right), k_{i}\left(\mathrm{mg} \cdot \mathrm{min}^{1 / 2} / \mathrm{g}\right.$ ) and $\mathrm{C}$ is constant are kinetics constant and the constant of the intra-particle diffusion model, respectively [22,23].

The calculated parameters listed in Table 1 exhibit that the adsorption data fit well with the pseudo-second-order kinetics.

The fitness of the pseudo-second-order kinetic model suggests that the $\mathrm{Cr}$ (III) and $\mathrm{Ni}$ (II) adsorption by both adsorbents is controlled by the chemisorption mechanism. Moreover, from the adsorption capacity values, the capacity enhancement is also found for both metal ions. The adsorption capacity for Cr by HAL is $30.37 \mathrm{mg} / \mathrm{g}$ increased into $41.88 \mathrm{mg} / \mathrm{g}$ by APTES/HAL. The enhancement also appears significantly for $\mathrm{Ni}$, which is about $19.63 \mathrm{mg} / \mathrm{g}$ in HAL to be $34.08 \mathrm{mg} / \mathrm{g}$ by APTES/HAL. The kinetics order and the capacity values describe the presence of chemical interaction caused by the APTES anchored on the halloysite surface. The ammine functional group has an affinity to bind with the metal ions via coordination bonding [24,25]. According to Pearson's theory (Hard \& Soft Acid-Base Theory), ammine functional groups are classified as intermediate ligands with high affinity towards transition metals, including $\mathrm{Cr}(\mathrm{III})$ and $\mathrm{Ni}(\mathrm{II})$. The electronegativity from the lone pair electrons of nitrogen and its weakly polarizable forced ammine functional group to bind with the small radii and weakly polarizable metal ions [26,27]. The schematic representation of the chemical interaction between metal ions and APTES is presented in Fig.5.
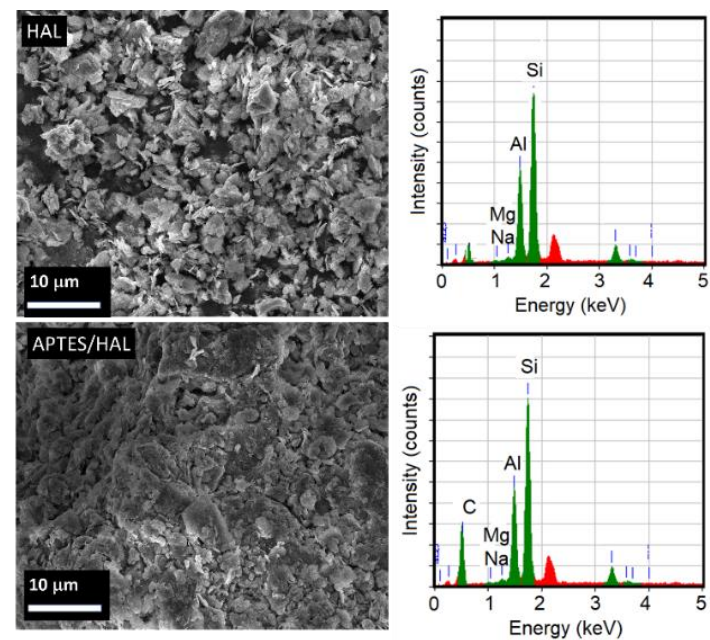

Figure 3. SEM-EDX analysis results of HAL and APTES/HAL.
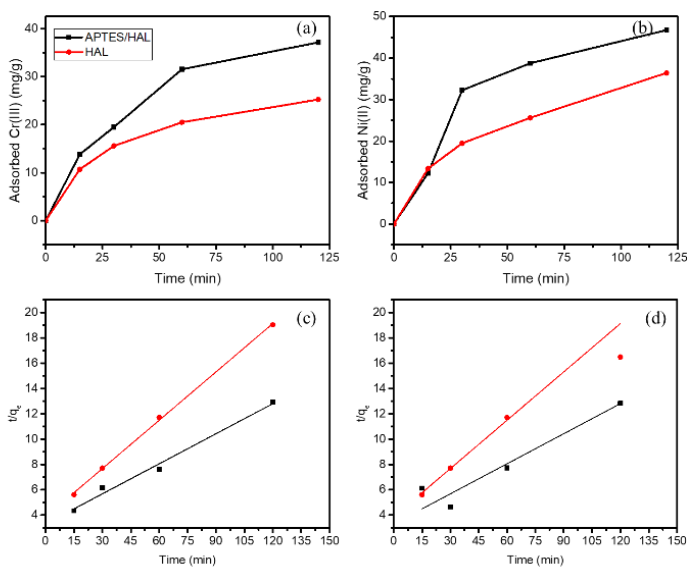

Figure 4. (a-b) Adsorption kinetics of $\mathrm{Cr}(\mathrm{III})$ and $\mathrm{Ni}(\mathrm{II})$ (c-d) pseudo-second-order plots of $\mathrm{Cr}$ (III) and $\mathrm{Ni}(\mathrm{II})$ adsorption. 
Table 1. Calculated parameters from kinetics studies.

Pseudo-first order kinetics

\begin{tabular}{|c|c|c|c|c|c|c|}
\hline & \multicolumn{3}{|c|}{$\mathrm{Cr}$ (III) } & \multicolumn{3}{|c|}{$\mathrm{Ni}(\mathrm{II})$} \\
\hline & $\mathbf{R}^{2}$ & $\mathbf{k}$ & Qe & $\mathbf{R}^{2}$ & $\mathbf{k}$ & $\mathbf{Q e}$ \\
\hline APTES/HAL & 0.994 & 0.364 & 3.28 & 0.930 & 0.199 & 0.32 \\
\hline HAL & 0.957 & 0.032 & 1.04 & 0.972 & 0.140 & 2.42 \\
\hline \multicolumn{7}{|c|}{ Pseudo-second-order kinetics } \\
\hline & \multicolumn{3}{|c|}{$\mathrm{Cr}($ III) } & \multicolumn{3}{|c|}{$\mathbf{N i}($ II $)$} \\
\hline & $\mathbf{R}^{2}$ & $\mathbf{k}$ & Qe & $\mathbf{R}^{2}$ & $\mathbf{k}$ & Qe \\
\hline APTES/HAL & 0.998 & 41.88 & 12.64 & 0.999 & 1.22 & 34.08 \\
\hline HAL & 0.994 & 30.37 & 7.86 & 0.990 & 0.77 & 19.63 \\
\hline \multicolumn{7}{|c|}{ Intra-particle diffusion } \\
\hline & $\mathbf{R}^{2}$ & $\boldsymbol{k}_{i}$ & $\mathrm{C}$ & $\mathbf{R}^{2}$ & $\boldsymbol{k}_{i}$ & $\mathbf{C}$ \\
\hline APTES/HAL & 0.989 & 0.0088 & -0.033 & 0.969 & 0.001 & 0.79 \\
\hline HAL & 0.989 & 0.419 & -0.423 & 0.984 & 0.540 & 0.002 \\
\hline
\end{tabular}

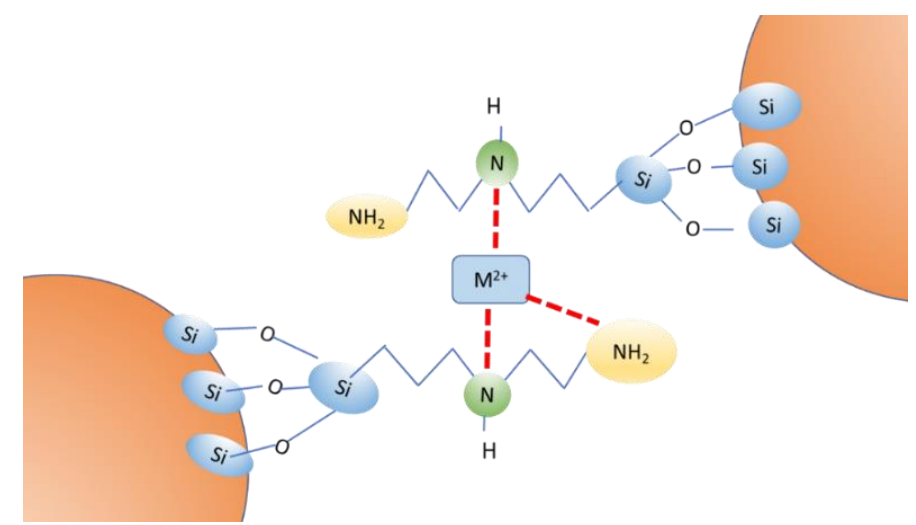

Figure 5. Schematic representation of adsorption interaction between APTES/HAL and metal ions.

\subsection{Adsorption isotherm.}

The detail of adsorbate-adsorbent interaction was evaluated by determining adsorption isotherm using two isotherm models; the Langmuir and Freundlich models. The equations for the Langmuir and Freundlich models are as follow (eq 4-5):

$$
\begin{aligned}
& q_{e}=K_{F} C_{e}^{1 / n} \\
& q_{e}=\frac{q_{m} K_{L} C_{e}}{1+K_{L} C_{e}}
\end{aligned}
$$

where $\mathrm{q}_{\mathrm{e}}$ and $\mathrm{q}_{\mathrm{m}}(\mathrm{mg} / \mathrm{g})$ are the adsorption capacity of the adsorbent at the equilibrium and maximum value, $\mathrm{Ce}(\mathrm{mg} / \mathrm{L})$ is the concentration of adsorbate in equilibrium, $K_{L}(\mathrm{~L} / \mathrm{mg})$ is the Langmuir constant related to the energy of adsorption, and $K_{F}$ and $n$ are the Freundlich constants related with adsorption-desorption equilibrium, and adsorption intensity, respectively $[28,29]$.

The $\mathrm{R}_{\mathrm{L}}$ parameter from the Langmuir isotherm is represented as follows (eq. 6):

$$
R_{L}=\frac{1}{1+K_{L} q_{m}}
$$

\begin{tabular}{|c|c|c|c|c|c|c|c|c|}
\hline \multirow{2}{*}{ Metal ion } & \multirow{2}{*}{ Adsorbent } & \multicolumn{3}{|c|}{ Freundlich Isotherm parameters } & \multicolumn{4}{|c|}{ Langmuir Isotherm Parameters } \\
\hline & & $K_{F}(L / g)$ & $1 / n$ & $\mathbf{R}^{2}$ & $\mathrm{q}_{\mathrm{m}}(\mathrm{mg} / \mathrm{g})$ & $\mathrm{K}_{\mathrm{L}}(\mathrm{L} / \mathrm{mg})$ & $\mathbf{R}_{\mathrm{L}}$ & $\mathbf{R}^{2}$ \\
\hline \multirow[t]{2}{*}{$\mathrm{Cr}$ (III) } & APTES/HAL & 26.28 & 0.31 & 0.992 & 45.08 & 0.04 & 0.999 & 0.998 \\
\hline & HAL & 1.78 & 0.57 & 0.998 & 26.23 & 1.28 & 1.050 & 0.928 \\
\hline \multirow[t]{2}{*}{$\mathrm{Ni}$ (II) } & APTES/HAL & 45.18 & 0.26 & 0.996 & 40.19 & 0.04 & 0.998 & 0.995 \\
\hline & HAL & 7.85 & 0.48 & 0.954 & 42.13 & 1.93 & 0.995 & 0.854 \\
\hline
\end{tabular}

Table 2 lists the calculated isotherm parameters.

Table 2. Calculated isotherm parameters. 
The $\mathrm{R}^{2}$ values represent that both models can be applied well for the $\mathrm{Cr}$ (III) and $\mathrm{Ni}$ (II) adsorption by APTES/HAL since the values are high $\left(\mathrm{R}^{2} \sim 1\right)$. The Freundlich plots are presented in Fig.6. However, the HAL adsorbent shows the Freundlich isotherm's fitness rather than the Langmuir isotherm, as the $\mathrm{R}^{2}$ value and the RL values are not appropriate to the model [30].
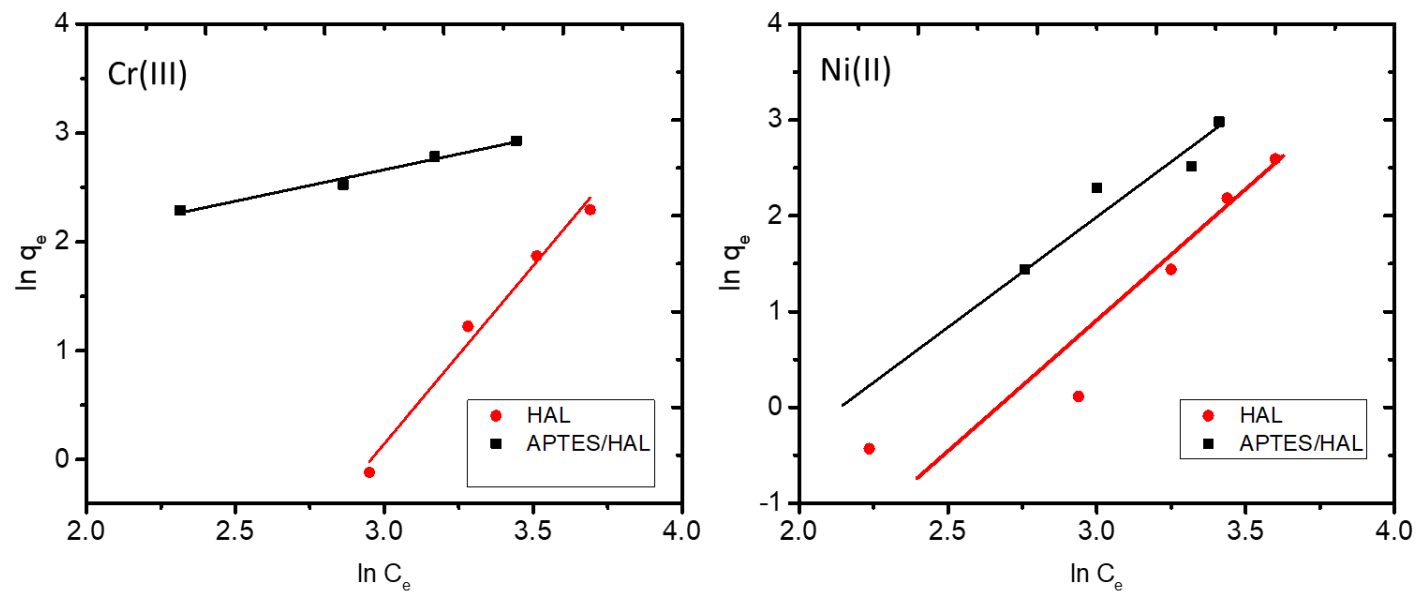

Figure 6. Freundlich isotherm plot of $\mathrm{Cr}(\mathrm{III})$ and $\mathrm{Ni}(\mathrm{II})$ adsorption.

Referring to RL values of the Langmuir isotherm model, the RL values laid at the range of $0<\mathrm{RL}<1$ indicate the favorable adsorption, and the data represents the inappropriateness of $\mathrm{Ni}$ (II) adsorption by HAL. Moreover, all $1 / \mathrm{n}$ values from the Freundlich isotherm are less than 1 , which validated the role of chemisorption on the adsorption sites. The KF values suggest that APTES/HAL demonstrates the higher adsorption/desorption equilibrium, meaning that the chemical equilibrium by APTES/HAL is more spontaneously occurred [10].

The isotherm data representing that the chemisorption interaction involved was confirmed by thermodynamic studies. The KF at varied temperatures were measured, and due to the adsorption standard free energy changes $\left(\Delta \mathrm{G}^{0}\right)$ equation (4):

$$
\Delta G^{0}=R T \ln K
$$

The average standard enthalpy change $\left(\Delta \mathrm{H}^{0}\right)$ is presented as (eq.5) :

$$
\ln K=-\frac{\Delta H^{0}}{R}\left(\frac{1}{T}\right)
$$

The average standard enthalpy values of $\mathrm{Cr}$ (III) and $\mathrm{Ni}$ (II) adsorption refer to the plot in Fig. 7, or called as vant' Hoff plot, is $44.3 \mathrm{~kJ} / \mathrm{mol}$ and $41.70 \mathrm{~kJ} / \mathrm{mol}$, respectively. The values are matched with the chemisorption qualification in terms of heat of adsorption, which is laid in the range of $40-100 \mathrm{~kJ} / \mathrm{mol}[25,31]$.

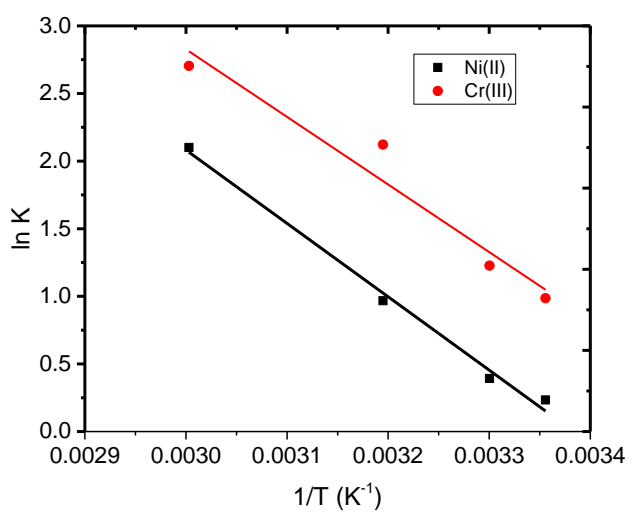

Figure 7. Van't Hoff plot of Cr(III) and Ni(II) adsorption by APTES/HAL. 


\section{Conclusions}

Adsorption kinetics and thermodynamics of $\mathrm{Cr}$ (III) and $\mathrm{Ni}$ (II) by using -[3(trimethoxysilyl)propyl] ethylenediamine -modified natural halloysite have been studied. The studies revealed the enhancement of adsorption capacity by surface modification with -[3(trimethoxysilyl)propyl] ethylenediamine. The adsorption kinetics studies indicate that the adsorption reaction obeys pseudo-second-order reaction, and the thermodynamic studies demonstrate the chemisorption involved in the mechanism. Generally speaking, the data exhibit the promising application of modified natural halloysite an adsorbent for metal ions in wastewater treatment.

\section{Funding}

This research received no external funding.

\section{Acknowledgments}

The authors thank Chemistry Department, Universitas Islam Indonesia, for financial support to this research.

\section{Conflicts of Interest}

The authors declare no conflict of interest.

\section{References}

1. Soliman, N.K.; Moustafa, A.F. Industrial solid waste for heavy metals adsorption features and challenges; a review. Journal of Materials Research and Technology 2020, 9, 10235-10253, https://doi.org/10.1016/j.jmrt.2020.07.045.

2. Ayob, S.; Othman, N.; Altowayti, W.A.H.; Khalid, F.S.; Bakar, N.A.; Tahir, M.; Soedjono, E.S. A Review on Adsorption of Heavy Metals from Wood-Industrial Wastewater by Oil Palm Waste. Journal of Ecological Engineering 2021, 22, 249-265, https://doi.org/10.12911/22998993/132854.

3. Qiu, B.; Tao, X.; Wang, H.; Li, W.; Ding, X.; Chu, H. Biochar as a low-cost adsorbent for aqueous heavy metal removal: A review. Journal of Analytical and Applied Pyrolysis 2021, 155, https://doi.org/10.1016/j.jaap.2021.105081.

4. Puglla, E.P.; Guaya, D.; Tituana, C.; Osorio, F.; García-Ruiz, M.J. Biochar from Agricultural by-Products for the Removal of Lead and Cadmium from Drinking Water. Water 2020, 12, https://doi.org/10.3390/w12102933.

5. Yang, J.; Huang, B.; Lin, M. Adsorption of Hexavalent Chromium from Aqueous Solution by a Chitosan/Bentonite Composite: Isotherm, Kinetics, and Thermodynamics Studies. Journal of Chemical \& Engineering Data 2020, 65, 2751-2763, https://doi.org/10.1021/acs.jced.0c00085.

6. Malovanyy, M.; Palamarchuk, O.; Trach, I.; Petruk, H.; Sakalova, H.; Soloviy, K.; Vasylinych, T.; Tymchuk, I.; Vronska, N. Adsorption Extraction of Chromium Ions (III) with the Help of Bentonite Clays. Journal of Ecological Engineering 2020, 21, 178-185, https://doi.org/10.12911/22998993/125545.

7. Hussain, S.T.; Ali, S.A.K. Removal of Heavy Metal by Ion Exchange Using Bentonite Clay. Journal of Ecological Engineering 2021, 22, 104-111, https://doi.org/10.12911/22998993/128865.

8. Chai, J.-B.; Au, P.-I.; Mubarak, N.M.; Khalid, M.; Ng, W.P.-Q.; Jagadish, P.; Walvekar, R.; Abdullah, E.C. Adsorption of heavy metal from industrial wastewater onto low-cost Malaysian kaolin clay-based adsorbent. Environmental Science and Pollution Research 2020, 27, 13949-13962, https://doi.org/10.1007/s11356-02007755-y.

9. Fatimah, I. Preparation, characterization and physicochemical study of 3-amino propyl trimethoxy silanemodified kaolinite for $\mathrm{Pb}(\mathrm{II})$ adsorption. Journal of King Saud University - Science 2018, 30, 250-257, https://doi.org/10.1016/j.jksus.2017.04.006.

10. Mao, S.; Gao, M. Functional organoclays for removal of heavy metal ions from water: A review. Journal of Molecular Liquids 2021, 334, https://doi.org/10.1016/j.molliq.2021.116143. 
11. Muhammad, A.; Shah, A.U.; Bilal, S. Effective Adsorption of Hexavalent Chromium and Divalent Nickel Ions from Water through Polyaniline, Iron Oxide, and Their Composites. Applied Sciences 2020, 10, https://doi.org/10.3390/app10082882.

12. Gray-Wannell, N.; Holliman, P.J.; Greenwell, H.C.; Delbos, E.; Hillier, S. Adsorption of phosphate by halloysite (7 ̊) nanotubes (HNTs). Clay Minerals 2020, 55, 184-193, https://doi.org/10.1180/clm.2020.24.

13. Jabłońska, B. Optimization of $\mathrm{Ni}(\mathrm{II}), \mathrm{Pb}(\mathrm{II})$, and $\mathrm{Zn}$ (II) Ion Adsorption Conditions on Pliocene Clays from Post-Mining Waste. Minerals 2021, 11, 568-579, https://doi.org/10.3390/min11060568.

14. Lim, S.; Park, S.; Sohn, D. Modification Of Halloysite Nanotubes For Enhancement Of Gas-Adsorption Capacity. Clays and Clay Minerals 2020, 68, 189-196, https://doi.org/10.1007/s42860-019-00059-4.

15. Kuśmierek, K.; Świątkowski, A.; Wierzbicka, E.; Legocka, I. Enhanced adsorption of Direct Orange 26 dye in aqueous solutions by modified halloysite. Physicochem. Probl. Miner. Process. 2020, 56, 693-701, https://doi.org/10.37190/ppmp/124544.

16. Gray-Wannell, N.; Holliman, P.J.; Greenwell, H.C.; Delbos, E.; Hillier, S. Adsorption of phosphate by halloysite (7 Å) nanotubes (HNTs). Clay Minerals 2020, 55, 184-193, https://doi.org/10.1180/clm.2020.24.

17. Falcón, J.M.; Sawczen, T.; Aoki, I.V. Dodecylamine-Loaded Halloysite Nanocontainers for Active Anticorrosion Coatings. Frontiers in Materials 2015, 2, 1-3, https://doi.org/10.3389/fmats.2015.00069.

18. Barman, M.; Mahmood, S.; Augustine, R.; Hasan, A.; Thomas, S.; Ghosal, K. Natural halloysite nanotubes /chitosan based bio-nanocomposite for delivering norfloxacin, an anti-microbial agent in sustained release manner. International Journal of Biological Macromolecules 2020, 162, 1849-1861, https://doi.org/10.1016/j.ijbiomac.2020.08.060.

19. Jang, E.-H.; Pack, S.P.; Kim, I.; Chung, S. A systematic study of hexavalent chromium adsorption and removal from aqueous environments using chemically functionalized amorphous and mesoporous silica nanoparticles. Scientific Reports 2020, 10, 1-20, https://doi.org/10.1038/s41598-020-61505-1.

20. Zhu, X.; Fan, X.; Wang, Y.; Zhai, Q.; Hu, M.; Li, S.; Jiang, Y. Amino modified magnetic halloysite nanotube supporting chloroperoxidase immobilization: enhanced stability, reusability, and efficient degradation of pesticide residue in wastewater. Bioprocess and Biosystems Engineering 2021, 44, 483-493, https://doi.org/10.1007/s00449-020-02458-7.

21. Jeamjumnunja, K.; Cheycharoen, O.; Phongzitthiganna, N.; Hannongbua, S.; Prasittichai, C. SurfaceModified Halloysite Nanotubes as Electrochemical CO2 Sensors. ACS Applied Nano Materials 2021, 4, 3686-3695, https://doi.org/10.1021/acsanm.1c00174.

22. Zou, C.; Liang, J.; Jiang, W.; Guan, Y.; Zhang, Y. Adsorption behavior of magnetic bentonite for removing $\mathrm{Hg}$ (ii) from aqueous solutions. RSC Advances 2018, 8, 27587-27595, https://doi.org/10.1039/c8ra05247f.

23. Lee, W.; Yoon, S.; Choe, J.K.; Lee, M.; Choi, Y. Anionic surfactant modification of activated carbon for enhancing adsorption of ammonium ion from aqueous solution. Science of The Total Environment 2018, 639, 1432-1439, https://doi.org/10.1016/j.scitotenv.2018.05.250.

24. Cheah, W.-K.; Sim, Y.-L.; Yeoh, F.-Y. Amine-functionalized mesoporous silica for urea adsorption. Materials Chemistry and Physics 2016, 175, 151-157, https://doi.org/10.1016/j.matchemphys.2016.03.007.

25. Yokoi, T.; Kubota, Y.; Tatsumi, T. Amino-functionalized mesoporous silica as base catalyst and adsorbent. Applied Catalysis A: General 2012, 421-422, 14-37, https://doi.org/10.1016/j.apcata.2012.02.004.

26. Alfarra, A.; Frackowiak, E.; Béguin, F. The HSAB concept as a means to interpret the adsorption of metal ions onto activated carbons. Applied Surface Science 2004, 228, 84-92, https://doi.org/10.1016/j.apsusc.2003.12.033.

27. Astier, C.; Chaleix, V.; Faugeron, C.; Ropartz, D.; Krausz, P.; Gloaguen, V. Biosorption of lead (II) on modified barks explained by the hard and soft acids and bases (HSAB) theory. Bioresources 2012, 7, 11001110 .

28. Dada A.O.; Olalekan A.P.; Olatunya A.M.; Dada O. Langmuir, Freundlich, Temkin and DubininRadushkevich Isotherms Studies of Equilibrium Sorption of Zn 2+ Unto Phosphoric Acid Modified Rice Husk. IOSR J. Appl. Chem. 2012, 3, 38-45, https://doi.org/10.9790/5736-0313845.

29. Khezrianjoo, S.; Revanasiddappa, H. Langmuir-Hinshelwood Kinetic Expression for the Photocatalytic Degradation of Metanil Yellow Aqueous Solutions by ZnO Catalyst. Chem. Sci. J. 2012, 2012, 85-85.

30. Camara L.D.T.; Neto A.J. Modeling of the Kinetics of Salycilic Acid Adsorption in Polymeric and Activated Charcoal Adsorbents. Ciencia 2008, 7, 49-54, http://dx.doi.org/10.5380/reterm.v7i1.61741.

31. Alasadi, A.M.; Khaili, F.I.; Awwad, A.M. Adsorption of Cu (II), Ni (II) and Zn (II) ions by nano kaolinite : Thermodynamics and kinetics studies. Chem. Inter. 2020, 5, 258-268, https://doi.org/10.5281/zenodo.2644985. 